\title{
Conditions and capacity for implementing Poland's vision zero
}

\author{
Kazimierz Jamroz ${ }^{1, *}$, Wojciech Kustra ${ }^{1}$, and Joanna Żukowska ${ }^{1}$ \\ ${ }^{1}$ Gdansk University of Technology, Faculty of Civil and Environmental Engineering, Gdansk, Poland
}

\begin{abstract}
Since 1991 Poland has been systematically reducing its traffic hazard. Despite considerable progress Poland is still among the most dangerous countries in the European Union. The key types of actions that help to reduce fatalities include enhancement of pedestrian safety, reducing the number of speeding drivers and eliminating or reducing hazard on the road. The paper presents a brief diagnosis of the state of road safety in Poland and a synthetic evaluation of the implementation of further national road safety programmes. It proposes measures necessary for achieving Vision Zero until 2050 (adopted by the EU) and an assessment of their effectiveness.
\end{abstract}

\section{Introduction}

It has been 20 years since the emergence of a new approach to measures to protect road traffic participants from injury and death. Sweden began the implementation of a new road safety policy called Vision Zero in 1996, which was adopted in the Swedish transport plan in 1997 $[1,2]$. Vision Zero refers to the philosophy of planning actions to improve road safety, although this philosophy was first applied in 1811 in the chemical company DuPont in the USA, where after a tragic accident involving explosives, the basic principles of safety were developed and responsibility for accidents was shifted to management. Moreover, a newly introduced requirement to document and analyse accidents and to create a working environment forgiving employees' mistakes led to enormous improvements in safety. To this day, the DuPont group remains a world leader in the field of occupational health and safety. Findings and ground breaking successes of safety measures applied by DuPont and the activity of Swedish chemical companies in the early 1990 (after an accident in a chemical plant in Seveso and Bohpal) are still important elements of "Vision Zero" which are also applied in the mining industry (mines) and transport [3].

The basic premise of "Vision Zero" in road transport is that serious accidents (fatal or serious injury) are not acceptable, and the long-term goal is to reduce their number to zero. According to the works of its authors [1,2] "Vision Zero" is:

- a philosophy of road safety planning, in which it is assumed that nobody should die or be seriously injured while using the road transport system.

- a long-term business strategy, involving the transformation of the road transport system and a change in the degree of responsibility between road users and vehicles (including the automotive industry) and the road and its surroundings (planners, designers and roads

\footnotetext{
Corresponding author: kjamroz@.pg.gda.pl
} 
maintenance system; the traffic enforcement system, rescue system and health care, government, parliament, etc.).

This approach, which states that nothing is more important than human life, puts road safety before any other assessment criteria of the functioning of the road transport system such as mobility, economy, environment. Ensuring mobility measured by the size and speed of transport is a basic requirement set for the road transport system. Total transport volume (traffic volume, the distance travelled by vehicles) affects the number of accidents, while speed influences the consequences of accidents (the share of fatalities and serious injuries). The search for the solution to the conflict between mobility and safety has stimulated a lot of innovation with increasing investments to develop a safe road transport system. The search goes towards increasing the role of speed surveillance systems or the use of ITS equipment [4]. Thus the question arises whether a non-negotiable ethical approach can compete with the economic approach? Is it possible to achieve the objectives of Vision Zero, how long will it take and at what costs? What social, economic, organisational obstacles can arise during its implementation?

Despite these concerns, many countries have adopted Sweden's idea of improving road safety including Norway, Denmark, Australia, Switzerland, the US [5-8]. Poland also adopted the Vision Zero in 2005 as an ethically legitimate vision of road safety [9].

Despite the growing interest in Vision Zero, there are no guidelines for politicians, transport planners, practitioners in the field of public health, the police and other people implementing road safety programmes according to the rules defined by Vision Zero, particularly at the strategic level. Decisions taken by the political authorities of the country, the Ministry of Transport and the Ministry of Infrastructure, at the strategic (political) level are significant (they have a very broad impact). They are made under conditions of uncertainty or risk arising from limited access to data, high volatility of the phenomenon and the lack of appropriate tools to facilitate decision making. Therefore, a variety of tools to facilitate strategic decision-making is required. To meet these expectations the article presents an analysis of the conditions and possibilities of achieving the objectives of Vision Zero in Poland by 2050 at a strategic level.

\section{Implementation of road safety programmes in Poland}

The EU is the world leader in road safety. A long-term vision is to eliminate or significantly reduce the number of road fatalities by 2050 . Four countries: Germany, France, Italy and Poland produce more than 50\% of road accident fatalities in the EU. Beginning from 1991, hazard in road traffic has been steadily decreasing in Poland, in the last 25 years the number of fatalities decreased by over $60 \%$. Despite such significant progress, Poland is still among the most dangerous countries in the European Union. Many times in the past 15 years, Poland has been in the first (worst) place among the countries of the European Union, taking into account the demographic mortality rate in road accidents. In 2015 Poland was number five in a ranking of 28 countries. Are things really that bad?

The risk of being a fatal victim in relation to the number of inhabitants in Poland is twice as high as the EU average, and even three times higher than the UK, the Netherlands and Sweden. But Poland is learning from the experience of other countries and uses it in a positive way (Fig. 1). 


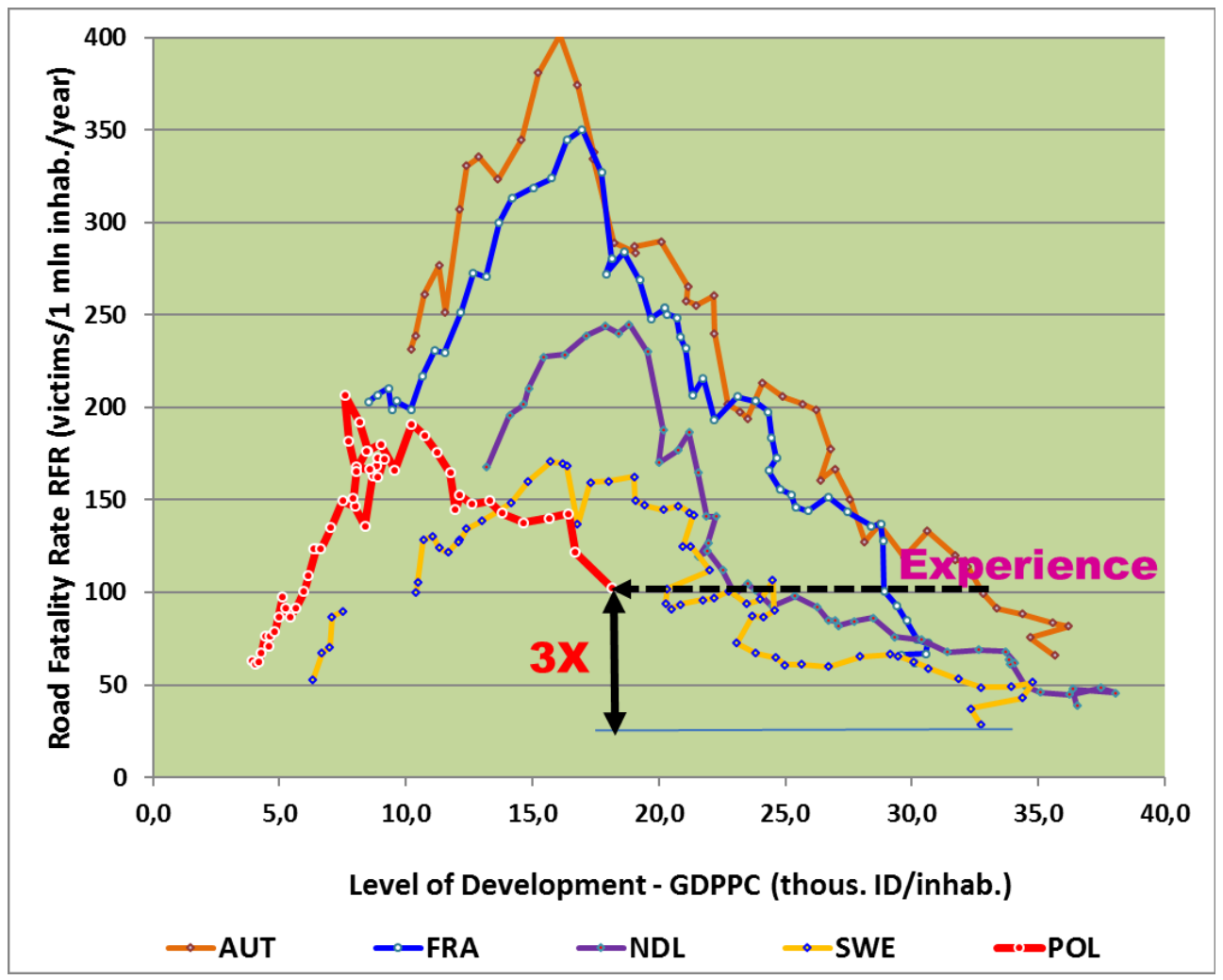

Fig. 1. Comparison of changes in the RFR in Poland with selected countries.

25 years ago (1991) in Poland the upward trend in the number of fatalities was broken. In 2005 Vision Zero was adapted as Poland's vision of road safety. Poland benefits from the experience of other countries, learns from them and uses the knowledge in its efforts to improve safety. This can be seen in Figure 1 with a comparison of road safety levels in Poland and France. The two countries have reached a level of safety - the RFR $=100$ fatalities per 1 million inhabitants at different periods of time and at different level of socio-economic development (measured by the level of GDP per capita in international dollars). In 2003 France had a GDP per capita $=30$ thousand ID, in Poland in 2012 the GDP per capita $=19$ thousand ID, i.e. a much lower level of socio-economic development. This demonstrates the early lessons learned, the result of taking advantage of the experience of advanced countries (the Netherlands, Sweden, the United Kingdom, France, etc.) in an effort to reduce the road accident mortality rate and to take systematic and programmatic actions.

Progress in the application of improvements and actions for road safety is slower than in other countries of the EU. The national road safety programmes have been the basis for a fatality reduction. The National Road Safety Programmes included: GAMBIT 1996, GAMBIT 2000, GAMBIT 2005 [10] and National Road Safety Programme by 2020 [11], GAMBIT for National Roads (2007-2013), as well as numerous regional and local road safety programmes [12]. In spite of the advanced implementation of the programmes the main problems of road safety in Poland persist: dangerous behaviour of road users (driving at dangerous speeds: $50 \%$ of drivers exceed speed limits, $27 \%$ of all fatalities); lack of pedestrian protection (pedestrians $-35 \%$ of deaths in road accidents, 1 st place in the EU); a poorly organised system of road safety (victims who died within 30 days after the accident 
still constitute $32 \%$ of total deaths); poor quality of road infrastructure (34\% of deaths on national roads which carry more than $25 \%$ of the traffic load); an unforgiving road environment (trees, poles) is the cause of $18 \%$ of total deaths. But there are positive effects of the road safety programmes, such as drink driving campaigns which led to a significant reduction in the share of fatal accidents of this type from $24 \%$ in 1995 to $11 \%$ in 2014 (which gives 25 th place in the ranking of the EU).

Therefore, Poland's road safety programmes (implemented in the last 20 years) put the emphasis on strengthening pedestrian safety, reducing excessive speeding and eliminating or reducing the impact of the various sources of danger (hazard) on the road. The progress of the programmes was analysed and assessed and shows that further measures to reduce the risk of traffic in Poland should be designed in accordance with the concept of the "three D's" on: continuation of the actions on infrastructure, including the completion of the network of higher class roads (motorways and express roads), development of safety management systems (with particular emphasis on automated supervision of dangerous behaviour of road users) and the promotion of safety culture among politicians, decision makers and road traffic participants.

\section{Analysis and evaluation of scenarios of actions for achieving Vision Zero}

In trying to answer the previous questions, several scenarios of the country's demographic and economic development and road safety system development were prepared. Using the previous studies [13-15] four scenarios were analysed that differ in terms of: population, national product and actions for road safety.

Scenario S1 represents low socio-economic development (18 thousand ID per capita in 2014 to 50.5 thousand ID per capita in 2050) and slight decrease in the number of inhabitants from 38.5 in 2014 to 36.3 million in 2050, lack of additional activities and interventions as well as limited operations of automated speed supervision systems (including reducing the number of speed cameras).

Scenario S2 represents low socio-economic development (50.5 thousand ID per capita in 2050) with an average decrease in the number of inhabitants to 33 million in 2050, initially a low number of additional actions, low number of actions and with time increase in the number of actions.

Scenario S3 represents average socio-economic development (62 thousand ID per capita in 2050) and an average decrease in the number of inhabitants to 33 million in 2050, quite a large number of additional organizational and infrastructural actions and change in the behaviour of road users.

Scenario S4 represents average socio-economic development (74 thousand ID per capita in 2050) and a high decrease in the number of inhabitants to 29.7 million in 2050, a large number of additional systemic actions (development of the health system, road safety system, automated traffic surveillance systems (speed cameras), decrease in the mobility of citizens, the development of a safe road infrastructure network (construction of motorways and expressways), etc.

To evaluate the scenarios the number of fatalities $\mathrm{F}$ was adopted. To estimate the number of road fatalities in the future from projected or assumed changes in social, economic and transport systems, the author's forecasting model was used, developed in the framework of the following works [12-16]. To estimate the number of fatalities, factor models were adopted in the general form shown in equations (1), (2), (3):

$$
F=P \cdot R F R_{b} \cdot M F_{c}
$$


where:

$$
\begin{aligned}
& R F R_{b}=\beta_{o} \cdot G D P P C^{\beta_{1}} \cdot V T K P C^{\beta_{2}} \cdot \exp \left(-\beta_{3} \cdot G D P P C-\beta_{4} \cdot L E I-\beta_{5} \cdot C P I+\beta_{6} \cdot A C P C+\right. \\
& \left.\beta_{7} \cdot D P R-\beta_{8} \cdot D M E-\beta_{9}\right) \\
& \quad M F_{c}=\gamma_{o} \cdot \exp \left(-\gamma_{1} \cdot L E I-\gamma_{2} \cdot D M E-\gamma_{3} \cdot \ln (\mathrm{FV})+\gamma_{4}\right)
\end{aligned}
$$

where:

$F$ - number of fatalities on the country's road network (fatalities/country/year), $P$ population (M inhabitants/country/year), $R F R_{b}$ - base road fatality rate (fatalities/1M inhabitants/year), $M F_{c}$ - country modification factor, GDPPC - gross national product per capita (thousands ID/inhabitant/year), (PPP, constant 2005, international \$), VKTPC average vehicle kilometres travelled per year per capita $(\mathrm{km} /$ population/year), LEI - life expectancy index, $C P I$ - corruption perception index, $A C P C$ - alcohol consumption per capita (1/inhabitant/year), $D P R$ - density of paved roads dependent on demography $(\mathrm{km} / 1 \mathrm{M}$ population), $D M E$ - density of motorways and expressways dependent on demography $\left(\mathrm{km} / 1 \mathrm{M}\right.$ population), $F V$ - number of speed cameras in use (cam./year), $\beta_{i}, \gamma_{i}$ - equation coefficients.

The base model - road fatality rate $(R F R)$ was developed from empirical data collected for selected countries which have trusted statistics of road fatalities, and in which there were no significant disturbances in the course of changes in accident mortality. Data was collected on the number of fatalities and the number of parameters characterising the selected countries in different years i.e. variables: geographic, demographic, economic, social, automotive, road and transport. The analyses helped to establish that in the base model the most important factors influencing the change of the $R F R$ indicator are: the level of socio-economic development represented by the individual gross domestic product ( $G D P P C$ ), the health care system and societal care for health represented by the index of life expectancy (LEI), inhabitants mobility level, measured by the average distance travelled by vehicles (VKTPC) and the structure of the road network represented by density of motorways and expressways $(D M E)$.

The application of the $M F_{c}$ coefficient modified the base model to match the national data. The result was a decrease in the mean squared error of the match of the estimated value $\mathrm{F}$ to the actual data. This allowed the model to be applied to the method for forecasting longterm changes in Poland's road fatalities. The resulting model correction (3) shows that Poland's road deaths can be reduced additionally through: LEI level of health care, development of the motorway and expressway network $D M E$ and development of an automated speed surveillance system $F V$.

Using the models for different scenarios, forecasts of changes were developed in the individual independent variables, used in the formulas (2) and (3). Next the number of deaths in the period 2014-2050 was estimated for the adopted scenarios. The results indicate that the expected further socio-economic development in Poland and the resulting changes in other independent variables (according to the trends currently observed among the countries with the highest road safety) will bring a systematic reduction in road fatalities. However, as the presented scenarios show, these changes will be insufficient to achieve the Vision Zero of road fatalities in 2050 .

If actions are taken as envisaged in scenario 3 or 4, the result can be up to 70,000 lives saved which means that Vision Zero can be achieved. Lack of consistency (e.g. removal of speed surveillance systems) can be dangerous as has been shown in scenarios 1 and 2. In fact, the risk of fatal accidents may rise in the initial period and there may be a significant reduction in the number of lives saved. This means that in these cases the implementation of Vision Zero will be very difficult, or even impossible. 


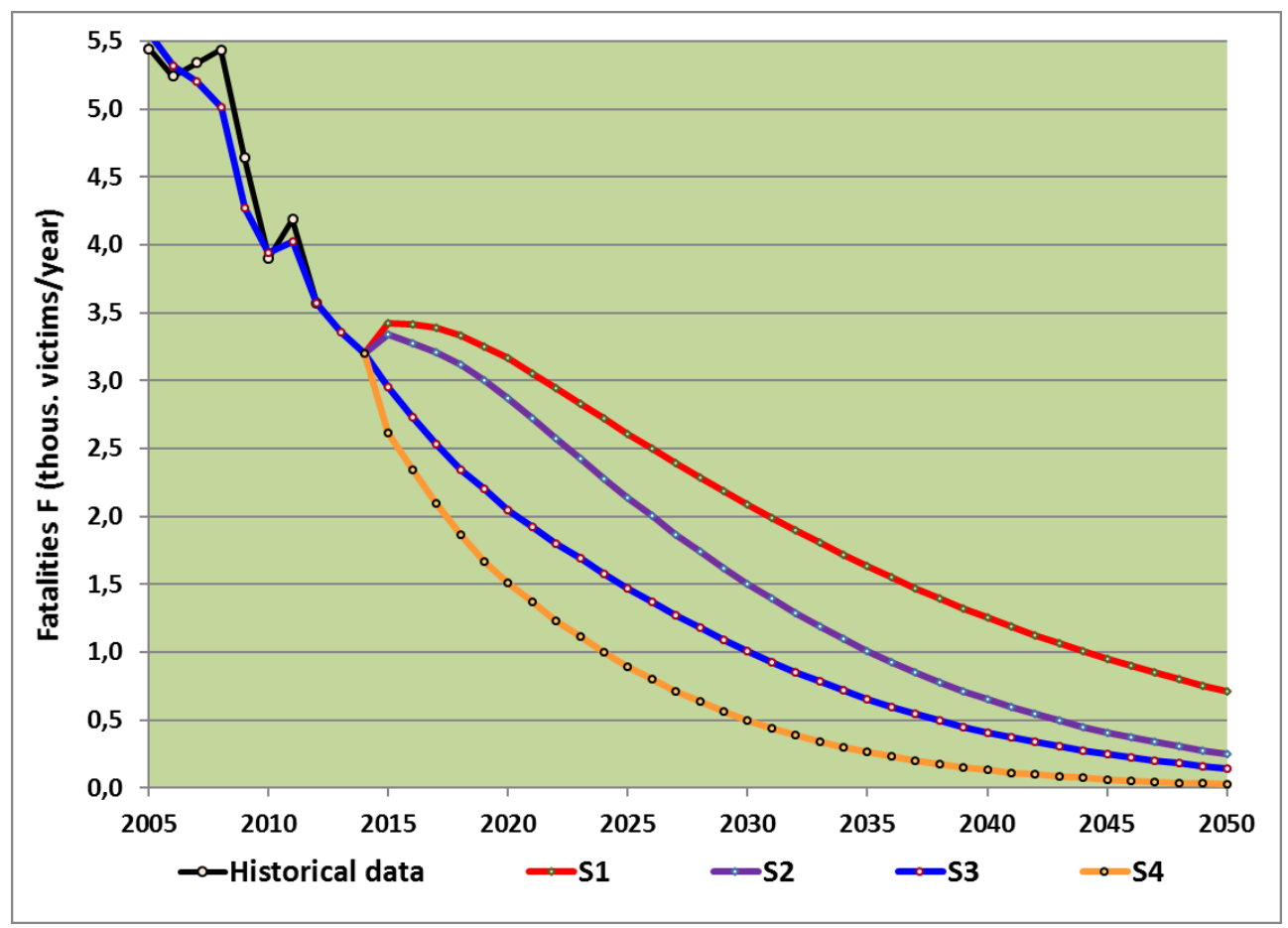

Fig. 2. Forecast of fatalities in Poland by 2050, taking into account different scenarios of external factors.

\section{Conclusions}

The results of the research and analyses made it possible to reach the following conclusions:

1. The trend change in the number of deaths in Poland has been favourable, since 1991 we have observed a systematic decrease in the "tragic harvest" on Polish roads.

2. Our society still pays too high a price (increase in fatalities and serious injuries) for unproven, often irresponsible and populist actions of the authorities (e.g. frequent changes in the structure and scope of the speed surveillance system, lack of decisive action for the protection of pedestrians, a road network with low standards of road safety).

3. The models for estimating the number of fatalities, proposed in this paper, help to estimate the risk of introducing selected road safety measures at the strategic level.

4. The analyses confirm that it is possible to achieve the objectives of Vision Zero in Poland around 2050, but only under the condition that numerous actions are carried out, with particular emphasis on: pedestrian protection, development of a speed management system, construction of safe roads, change in the safety culture, etc.

5. It is necessary to conduct further research (e.g. on the number of victims seriouslyinjured, accident costs, etc.) to improve the presented models and further develop the safety measures; the models should be used to develop and implement in practice modern management methods of road safety. 


\section{References}

1. C. Tingvall, The Swedish "Vision Zero" and how parliamentary approval was obtained, in: Road Saf. Res. Policing, Educ. Conf., (Wellington, New Zealand, 1998)

2. C. Tingvall, N. Haworth, Vision Zero - An ethical approach to safety and mobility, in: 6th ITE Int. Conf. Road Saf. Traffic Enforc. Beyond 2000, (Melbourne, 1999)

3. H. Ehnes, Vision Zero - The New Global Strategy for Safe Mining, in: Int. Symp. Cult. Prev. - Futur. Approaches From Risks To Vis. Zero, (Finnish Institute of Occupational Health, 2014)

4. L.C. Wadhwa, Vision Zero requires five-star road safety system, in: Road Saf. Res. Polic. Educ. Conf., (Melbourne, Australia, 2001)

5. A. Erke, R. Elvik, Making Vision Zero real: Preventing pedestrian accidents and making them less severe. TOI report 889/2007 (Oslo, 2007)

6. D. Atkins, M. Granhed, Vision Zero: Applying road safety to avalanche safety, in: Int. Snow Sci. Work., (Anchorage, Alaska, 2012)

7. A. Fleisher, M.L. Wier, M. Hunter, A Vision for Transportation Safety: 1 A Framework for Identifying Best Practice Strategies to Advance Vision Zero, TRB. (2016)

8. WHO, Global Plan for the Decade of Action for Road Safety 2011-2020 (2011)

9. K. Jamroz, L. Michalski, S. Gaca, Road safety programmes as an effective tool for developing system-based road safety policies, J. Konbin. 1 pp. 155-160 (2006)

10. L. Michalski, K. Jamroz, J. Żukowska, UN Decade of action for road safety in the national road safety strategy until 2020 - Polish approach, in: 16th Int. Conf. Road Saf. Four Cont., (Beijing, China, 2013)

11. National Road Safety Programme for 2013-2020 (Polish National Road Safety Council, Warsaw, 2013)

12. K. Jamroz, Is Vision Zero realistic in Poland?, in: 4th Int. Conf. Road Saf. Simul., (Roma, 2013)

13. K. Jamroz, The impact of road network structure and mobility on the national traffic fatality rate, Procedia - Soc. Behav. Sci. 54 pp. 1370-1377 (2012). doi:10.1016/j.sbspro.2012.09.851

14. K. Jamroz, L. Smolarek, Road safety management tools for country strategic level, in: 16th Road Saf. Four Cont. Conf., (Beijing, China, 2013)

15. K. Jamroz, W. Kustra, M. Budzyński, J. Żukowska, Pedestrian Protection, Speed Enforcement and Road Network Structure the Key Action for Implementing Poland's Vision Zero, Transp. Res. Procedia. 14 pp. 3905-3914 (2016). doi:10.1016/j.trpro.2016.05.479

16. K. Jamroz, Method of risk management in highway engineering. Metoda zarzadzania ryzykiem w inżynierii drogowej (Gdansk University of Technology, Gdansk, 2011) 